\title{
Experimental Study on Low-Frequency Oscillating Behavior in Mechanically-Ventilated Compartment Fires
}

\author{
M. Mense ${ }^{1}$, Y. Pizzo ${ }^{2,3}$, H. Prétrel ${ }^{1}$ and B. Porterie ${ }^{2,3}$ \\ ${ }^{1}$ Institut de Radioprotection et de Sûreté Nucléaire (IRSN), PSN-RES, SA2I, Laboratoire commun ETiC, \\ Cadarache, 13115 Saint-Paul-Lez-Durance, France \\ ${ }^{2}$ Aix-Marseille Université (AMU), CNRS, IUSTI UMR 7343, Laboratoire commun ETiC, 13453 Marseille, \\ France \\ ${ }^{3}$ RS2N, 83640 Saint-Zacharie, France
}

†Corresponding Author Email: maxime.mense@irsn.fr

(Received May 31, 2018; accepted July 10, 2018)

\begin{abstract}
This study focuses on fire behavior in a mechanically-ventilated compartment, with a special emphasis on the low-frequency (LF) oscillatory behavior that has been occasionally observed. LF oscillations, typically in the order of a few $\mathrm{mHz}$, can lead to large thermodynamic pressure variations, which in turn can cause fire safety issues (e.g. loss of confinement, mechanical damages). To address these issues, small-scale experiments are conducted varying the air renewal rate (ARR) in the compartment from 8 to $20 \mathrm{~h}^{-1}$ and the ventilation configuration. The fire source consists of heptane fuel loaded in a pan with a diameter of $18 \mathrm{~cm}$. Depending on the ARR, LF oscillations are observed on the time evolution of the burning rate, and thus of all the other variables, with a frequency in the range of $16-26 \mathrm{mHz}$. As the ARR increases, there are three distinct regimes of burning behavior observed in this study: (1) rapid extinction due to smoke filling; (2) LF oscillating burning, followed by blow-off extinction after a few oscillations; and (3) LF oscillating burning, where extinction occurs because of the burning rate "runaway" due to an intensification of the heat transfer through the rim of the container. The oscillatory behavior and fire extinction result from the competition between oxygen supply and fuel vapor supply due to the heat feedback to the fuel tray. Both regimes (2) and (3) are accompanied by displacements of the flame out of the pan towards regions where oxygen is present. The influence of ARR and ventilation configuration (i.e. air inlet location and blowing direction) on the burning rate and LF oscillation properties (frequency, amplitude) is examined and discussed.
\end{abstract}

Keywords: Compartment fire; Forced ventilation; Experiments; Oscillating flame.

\section{NOMENCLATURE}

ARR Air Renewal Rate

FFT Fast Fourier Transform

HRR Heat Release Rate

\section{INTRODUCTION}

Naturally-ventilated compartment fires may exhibit oscillating combustion depending on the compartment size and ventilation factor $\mathrm{AH}^{1 / 2}$, where $\mathrm{A}$ is the area of the ventilation opening and $\mathrm{H}$ is its height. A large body of literature was devoted to such a phenomenon (e.g. Takeda and Akita, 1981, Takeda, 1985; Sugawa et al., 1989; Utiskul et al., 2005; Utiskul and Quintiere, 2008). Oscillations of the burning rate were observed, with frequencies of around $1 \mathrm{~Hz}$, which is of the same order of magnitude as those observed in free atmosphere conditions (f $\sim 1.5 / \mathrm{D}^{1 / 2}$, where $\mathrm{D}$ is the diameter of the fuel pan

$\begin{array}{ll}\text { LF } & \text { Low-Frequency } \\ \text { MLR } & \text { Mass Loss Rate } \\ \text { X } & \text { mole fraction }\end{array}$

(Zukoski et al., 1984), leading here to $\mathrm{f}=3.5 \mathrm{~Hz}$ ). The only work where low-frequency (LF) oscillations, significantly less than $1 \mathrm{~Hz}$, were observed is the work of Kim et al. (1993). From experiments conducted in a small-scale compartment with a single door-like opening, Kim et al. (1993) obtained oscillations on gas temperature histories of about 22 $\mathrm{mHz}$ for the lowest ventilation factor considered. Oscillating behavior of naturally-ventilated fires is generally accompanied by small thermodynamic pressure variations. Depending on compartment dimensions and fire size, low ventilation conditions can also lead to singular flame behaviors, such as oscillating and ghosting flames. A ghosting flame is 
a flame that can detach from the fuel surface and travel around the compartment seeking oxygen and flame oscillation describes phenomenon where the flame is shrinking to extinction, but cycles back to its original size. Such behaviors were observed by many authors (Sugawa et al., 1989; He et al., 2015, Matsuyama et al., 2015; Bertin et al., 2002; Wakatsuki, 2001, to name but a few).

For fires in enclosures equipped with mechanical ventilation, such as in nuclear facilities, low-frequency oscillatory behavior can be encountered, leading to large pressure variations that can affect the confinement levels and hence the safety of the installation. This LF oscillatory behavior was observed by Audouin et al. (2013) and Prétrel et al. (2016) from experiments on heptane pool fires in the large-scale DIVA facility of IRSN (Institut de Radioprotection et de Sûreté Nucléaire). They reported frequencies in the range of $5-7 \mathrm{mHz}$ for 0.5 MW heptane pool fires and air renewal rates between 12 and $17 \mathrm{~h}^{-1}$. During this oscillatory phase, a drastic change in flame behavior occurred: the flame emission intensity decreased, and a weakly blue flame left the pool surface and moved slowly through the compartment, before coming back above the pan. This behavior is similar to that observed for naturallyventilated fires, but with a larger oscillation period and amplitude, and larger pressure variations.

The purpose of this research is to evaluate the effect of forced ventilation conditions on the LF oscillatory behavior of heptane pool fires. To address this challenge, experiments using a 1:4 scale reproduction of DIVA, called NYX, are carried out, varying the air renewal rate (ARR) and ventilation configuration (i.e. air inlet location and blowing direction).

\section{EXPERIMENTAL SET-UP}

The experimental apparatus NYX is a $1.5 \mathrm{~m} \times 1.25$ $\mathrm{m} \times 1 \mathrm{~m}$ mechanically-ventilated compartment (Fig. 1). Froude similarity criterion is used for scaling gas flow rates between DIVA and NYX. In NYX, the side walls, namely E (East), S (South), N (North), B (Back) and F (Front) are composed of two layers, a 2-mm-thick steel layer and a 45-mm-thick calcium silicate layer. A transparent heat-tempered glass window, installed on the West (W) wall, allows visualization of the fire phenomena and video recording. The inlet airflow is free whereas hot gases are extracted mechanically. Ventilation ducts have a diameter of $4 \mathrm{~cm}$. Inlet and exhaust ducts are situated in the upper part of the room, near the ceiling. The fuel is located at the center of the box. Heptane fuel $\left(\mathrm{C}_{7} \mathrm{H}_{16}\right)$ is burned in a cylindrical stainless-steel pan, with a diameter of $18 \mathrm{~cm}$ and a height of $5 \mathrm{~cm}$. All the tests are conducted with a similar initial lip height of $7 \mathrm{~mm}$. The initial fuel mass is around $750 \mathrm{~g}$. Ignition is performed using a propane gas burner.

Measurements comprise fuel mass loss, gas temperature, differential pressure, and mole fraction of oxygen. A SARTORIUS $\AA$ load cell is used to measure the fuel mass loss over time (Fig. 1). Four vertical trees of five 0.5 -mm-diameter type-K thermocouples are used to measure gas temperature in each room corner. Mole fractions of $\mathrm{O}_{2}$ are measured by five gas analyzers (Xstream and Siemens Ultramat23): one positioned near the fuel pan, one in the BW corner at a height of $42 \mathrm{~cm}$, two in the FE corner at heights of 42 and $83 \mathrm{~cm}$, and one in the exhaust duct.
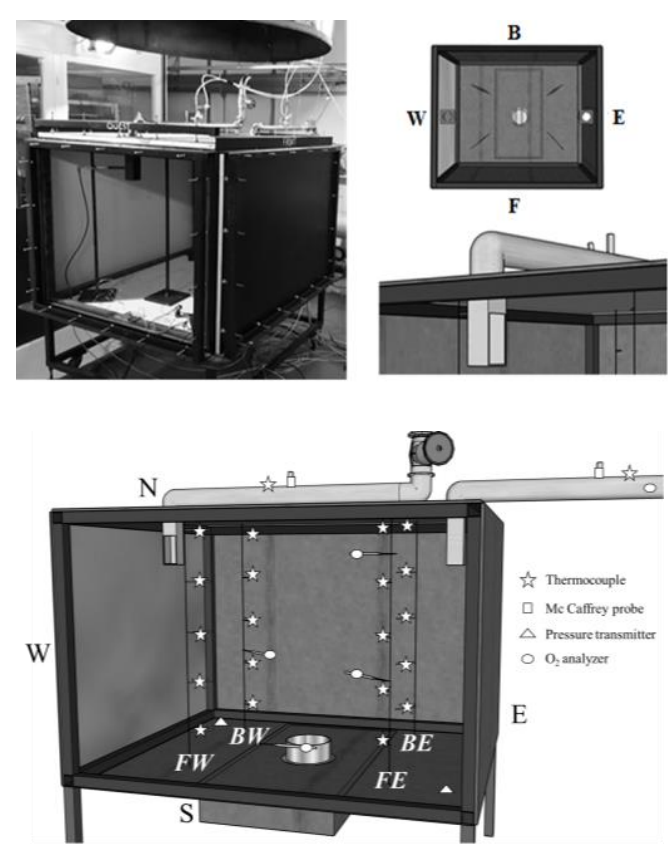

Fig. 1. Picture and schematic diagram of the experimental setup NYX showing instrumentation.

Two bi-directional probes developed by McCaffrey and Heskestad (1976), calibrated beforehand, are positioned in the ventilation ducts to monitor inlet and outlet flow velocities. Each probe is connected to a differential pressure transducer with a pressure range of -1000 to $1000 \mathrm{~Pa}$. Local temperature is measured by a type-K thermocouple to compensate for gas density variations caused by temperature changes. Two Emerson ROSEMOUNT pressure transmitters, located on the floor in the corner BW and $\mathrm{FE}$, are used to measure pressure differences between the inside and outside of the compartment. Data are taken at a scan rate of $1 \mathrm{~s}$.

This paper is based on a series of tests in which the effects of the air renewal rate (ARR), defined as the ratio between the inlet air flow rate before ignition and the compartment volume, on 18-cm-diameter heptane pool fires under forced ventilation are examined.

\section{LOW-FREQUENCY OSCILLATORY FIRE BEHAVIOR}

In this section, the 18-cm-diameter heptane pool fire at an ARR of $15 h^{-1}$, is used to exemplify the lowfrequency oscillatory fire behavior.

\subsection{Observations}

Figure 2 shows the time evolution of the mass loss 
rate (MLR) of heptane. Oscillations appear immediately after ignition, but after $250 \mathrm{~s}$ of fire, the period and amplitude of these oscillations significantly increase. We clearly identify between 250 and $500 \mathrm{~s}$, five low-frequency oscillation cycles with a period of each around $50 \mathrm{~s}$, leading to a frequency in the order of $20 \mathrm{mHz}$. The analysis of the video captured frames shows how these oscillations are related to the displacement and geometry of the visible flame. In this unstable combustion regime, the extinction, which occurs after $496 \mathrm{~s}$ of fire, follows the oscillatory period, as it was also observed by Kim et al. (1993).
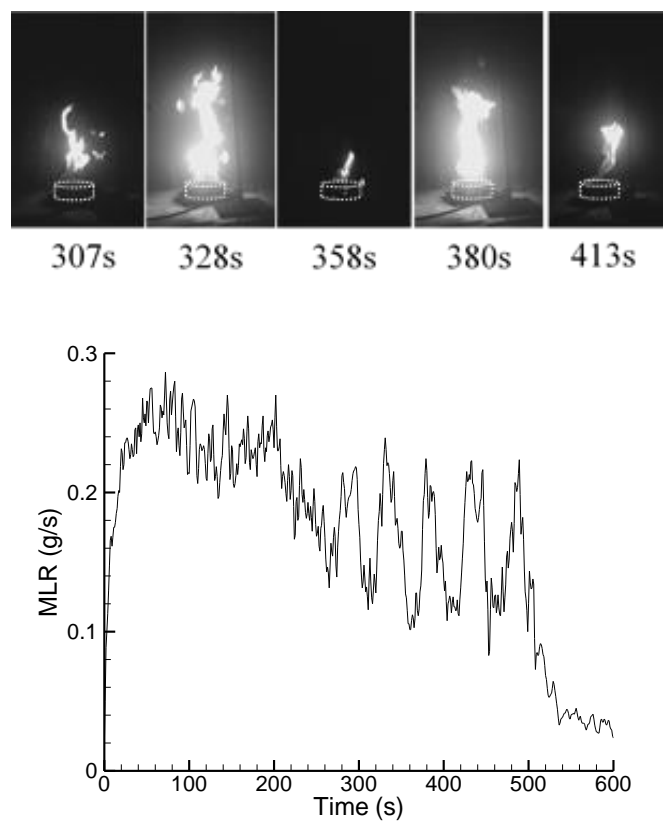

Fig. 2. Video captured frames after $307,328,358$, 380 and $413 \mathrm{~s}$ of fire, and MLR vs. time.

Let us focus now on the period from 328 to $380 \mathrm{~s}$. At $328 \mathrm{~s}$, the flame is above the pan and the heat feedback from the flame to the fuel surface is high, leading to a maximum in MLR. Subsequently, due to oxygen depletion, the flame becomes smaller and less intense. The flame is lifted and leaves the pool surface (oscillating flame) or occupies only a part of it. Concomitantly, the burning rate decreases and goes through a minimum. When the flame comes back above the pan, the MLR increases again. The period of the oscillation corresponds to the time interval between two maximums of MLR with a visible flame height, here in the order of about $52 \mathrm{~s}$. Video captured frames also show that several changes occur in the flame structure and appearance. When the flame leaves the fuel pan, it changes in intensity and color, from yellow to bluish-yellow, and appears less turbulent, which results from a reduction in the flaming fuel surface area, and thus in the MLR (Takeda and Akita, 1981; Mizukami et al., 2016). Moreover, for this configuration of ventilation, observations show that the flame migrates to the FE corner when it leaves the pool surface.
Oscillations on the MLR lead to oscillations on other variables like the differential pressure between the inside and the outside of the compartment, the mole fraction of oxygen and gas temperature in the enclosure, and the inlet and outlet flow rates, as shown on the time evolutions given in Fig. 3. A Fast Fourier Transform (FFT) of these curves yields a similar dominant frequency of around $20 \mathrm{mHz}$. We can also observe in Fig. 3 that oscillations of the differential pressure, outlet flow rate ( $\left.Q_{\text {out }}\right)$, and gas temperature are nearly in phase with those of MLR, whereas the inlet flow rate $\left(Q_{\text {in }}\right)$ and the oxygen mole fraction are nearly in phase opposition. Figure 3(a) shows the large variations of the differential pressure in the LF oscillatory phase, between 250 and $500 \mathrm{~s}$, in the order of a few hundred Pascal.

Gas temperatures in the compartment follow the evolution of the MLR (Figs. 3(b) and 3(c)). Along the central axis of the compartment (Fig. 3(b)), the temperatures measured at heights of $0.15 \mathrm{~m}$ and 0.85 $\mathrm{m}$ exhibit the same oscillatory trend. However, the former is higher, because of its proximity to the fuel surface, and oscillates with a higher amplitude, as it is very sensitive to flame movements. When the flame is above the pan, gas temperature can exceed $750^{\circ} \mathrm{C}$, whereas it can decrease down to $150^{\circ} \mathrm{C}$ as the flame is lifted and leaves the pool surface or does not spread over all the fuel surface, because of the insufficient air supply. By contrast, gas temperatures measured in the BW corner (Fig. 3(c)) increase with height, as well as the oscillation amplitude. The highest thermocouples are more influenced by the ceiling jet produced by impingement of the fire plume on the ceiling. Figures 3(d) and 3(e) represent the evolutions with time of the mole fractions of oxygen measured in the lower and upper parts of FE and BW corners, and in the exhaust duct. Oxygen mole fractions decrease rapidly to about $15-16 \%$ in the first $200 \mathrm{~s}$ of fire, and then fluctuate more or less around a value of about $15 \%$ in the upper part of the compartment and a value of about $16 \%$ in the lower part.

After $200 \mathrm{~s}$, fire continues to burn in a vitiated environment and ventilation is not sufficient to sustain a fully-developed fire. The flame oscillates five times before blow-off extinction which occurs before the fuel is completely exhausted.

As shown in diagram (f) of Fig. 3, the inlet air flow rate and the MLR time evolutions are in phase opposition. It can also be observed that the fluctuations of the inlet air flow rate are more important than those of the exhaust flow rate. This can be explained by the high aeraulic resistance of the outflow branch (the flow rate is regulated by a valve located in the ventilation network), unlike the inlet branch where fresh air enters the compartment freely through a passive vent.

\subsection{Interpretation of the LF Oscillatory Behavior}

The observations reported in the previous section 

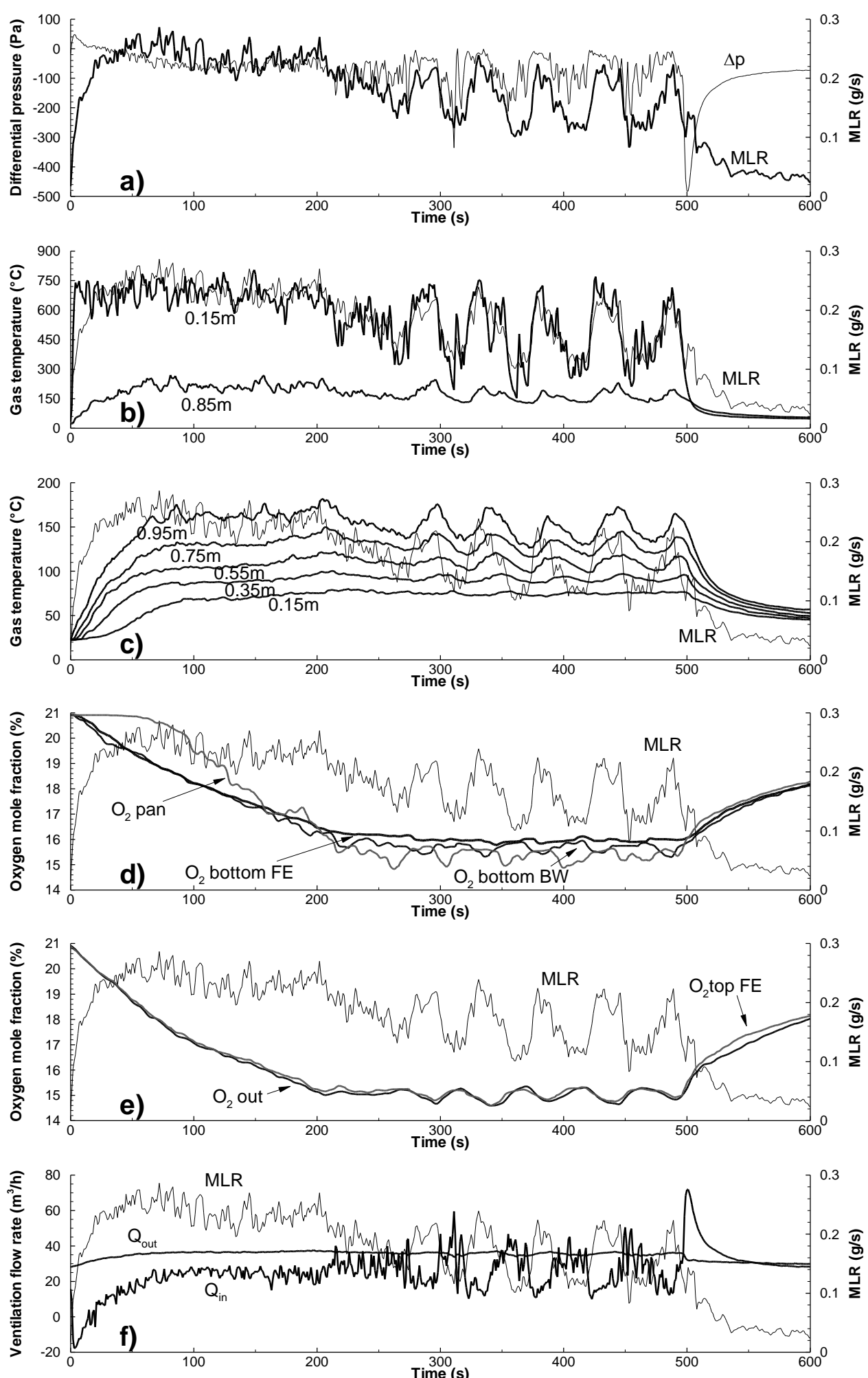

Fig. 3. Time evolution of (a) differential pressure, (b) gas temperature along the central axis at heights of 0.15 and $0.85 \mathrm{~m}$, (c) gas temperature at different heights in the corner FE, (d) oxygen mole fraction in the lower part of the compartment and near the fuel pan, (e) oxygen mole fraction in the upper part of the compartment and in the exhaust duct (see Fig. 2 for the position of oxygen analyzers), and (f) inlet and outlet flow rates. For easier analysis, the time evolution of MLR is superimposed on each diagram.

allow us to propose an explanation for the occurrence and persistence of LF oscillatory burning behavior. When the flame is positioned vertically above the pan, the heat feedback to the fuel surface increases. Due to the increasing of the burning rate, and thus the heat release rate, the pressure and the temperature 
in the compartment increase. This leads to a reduction in the air inlet flow rate. The amount of oxygen supply is not large enough to sustain a strong combustion. The flame is lifted and leaves the pool surface or does not spread over all the fuel surface. It changes in color, from yellow to bluish-yellow, and becomes less intense. The heat feedback decreases, and thus the MLR. This is followed by a reduction in pressure and temperature in the compartment, leading to an increase in the inflow rate, which provides more oxygen to support combustion. The flame recovers its position above the fuel pan. This cycle can be repeated many times (Fig. 4).

The persistence of the LF oscillations depends on the precarious equilibrium between the oxygen supply and the fuel vaporization due to the heat feedback from the flame and enclosure to the fuel tray. This equilibrium can be broken at any time, which leads to extinction (Takeda and Akita, 1981; Kim et al., 1993). From small-scale experiments Kim et al. (1993) showed that the gas temperature in the compartment became higher as the oscillation repeated, increasing the temperature of the fuel tray and thus the emission of fuel vapor. The air supply was not large enough to balance the fuel vapor supply and extinction occurred.

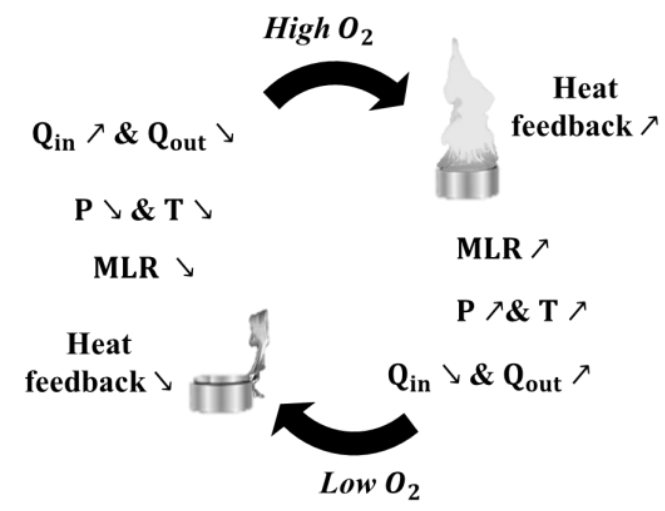

Fig. 4. Illustration of mechanisms leading to LF oscillations.

\section{INFLUENCE OF RENEWAL RATE}

In this section, we study the influence of the air renewal rate of the compartment on the LF oscillatory burning behavior, using a constant diameter of the heptane pool, i.e. $18 \mathrm{~cm}$.

Time evolutions of MLR of the heptane pool fire for ARR between 8 and $20 \mathrm{~h}^{-1}$ are given in Fig. 5. First, we can observe that in the first 200 seconds, these evolutions are similar, which suggests that during this period, the combustion is slightly influenced by the ventilation (fuel-controlled fire). Subsequently, three different unstable regimes of fire are identified depending on the air renewal rate.

For ARR $\leq 8 \mathrm{~h}^{-1}$, rapid extinction due to filling. The compartment is filled practically completely with smoke and the air supply is not large enough to sustain gas combustion.
For $10 \leq \mathrm{ARR} \leq 15 \mathrm{~h}^{-1}$, extinction occurs as a blowoff after a few oscillations. The heat feedback from the flame and enclosure is not strong enough to sustain fuel pyrolysis. In this regime, the flame, which moves outside the pan, comes back above the pan with difficulty.

For $A R R \geq 16.5 \mathrm{~h}^{-1}$, the air supply is sufficient enough to sustain combustion for a long time. The MLR, and thus the heat release rate, slightly increase with the air supply. Extinction occurs due to the enhancement of the burning rate which results from the increase of heat transfer through the rim of the container, making easier the vaporization of the small quantity of liquid fuel remaining in the pan. At the moment of extinction, it remains approximately $300 \mathrm{~g}$ of heptane in the pan. As the MLR increases with the ARR, the higher the ARR, the sooner the extinction occurs. This is clearly seen by comparing diagrams (e) to (g) of Fig. 5. In this regime, we can observe that the frequency of oscillations increases with ARR, while their amplitude decreases with rising ARR. We can also show a trend to steady-state as the air supply increases, as observed by Takeda and Akita (1981) or Kim et al. (1993) from naturallyventilated pool fires. This suggests that the rates of air supply and fuel vapor supply are getting better and better balanced. Although the ventilation rate is greater than 3.6 times the stoichiometrically required air, the time-averaged value of the MLR for the higher ARR considered, approximately 0.23 g. $\mathrm{s}^{-1}$, is half that of free burning, deduced for an heptane pool fire with a diameter $D$ from the following relationship: $\quad M L R=$ $101 \pi D^{2}[1-\exp (-1.1 D)] / 4=\quad 0.46 \mathrm{~g} \cdot \mathrm{s}^{-1}$ (Zabetakis and Burgess, 1961; Babrauskas, 1983).

Figures 6 and 7 support the above-mentioned statements. For $A R R=8 \mathrm{~h}^{-1}$, oxygen depletion and smoke filling are responsible for extinction, with an oxygen mole fraction in the lower part of the FE corner that drops down to $15.2 \%$, which is very close to the limiting oxygen concentration for heptane (about 14\% in Loo et al., 2013) (Fig. 6). For $\mathrm{ARR}=15 \mathrm{~h}^{-1}$, oxygen mole fraction stabilizes around $16 \%$, but the heat feedback is too low to sustain combustion, as suggested by the gas temperaturetime curve (Fig. 7). For higher ARR, gas temperature increases with time, increasing the heat feedback to the fuel surface, which in turn delays extinction until the effects of conduction through the rim of the pan lead to extinction.

The experimental results indicate the influence of ARR on the oscillation frequencies. Table 1 gives the dominant frequencies deduced from a spectral FFT analysis of the time evolutions of MLR, differential pressure, oxygen mole fraction, and gas temperature for ARR in the range of $10-18 \mathrm{~h}^{-1}$. Firstly, for a given ARR, the frequencies are very close to each other. Secondly, the frequency increases with the ARR, in average from 16 to $26 \mathrm{mHz}$ (corresponding to periods from 38 to $63 \mathrm{~s}$ ). This trend is similar to the one observed in large-scale experiments by Prétrel $e t$ al. (2016). 
M. Mense et al. /JAFM, Vol. 12, Special Issue, pp. 49-58, 2019.
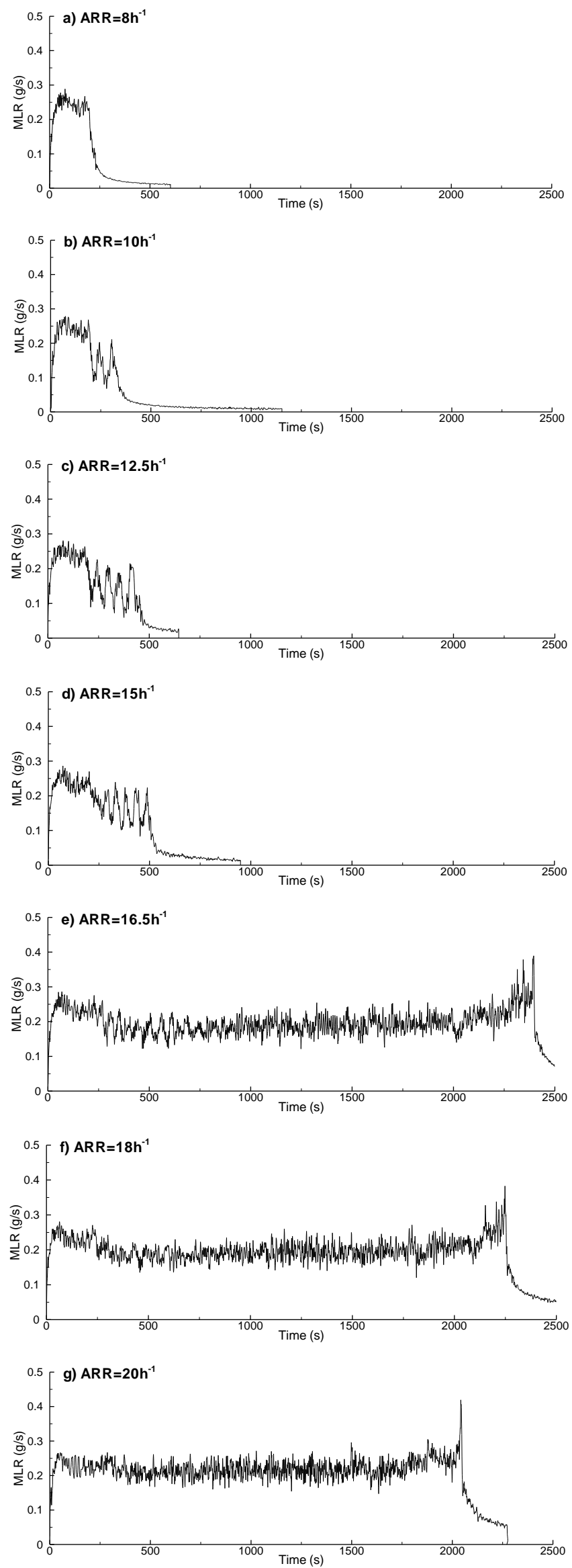

Fig. 5. MLR vs. time for different air renewal rates. 


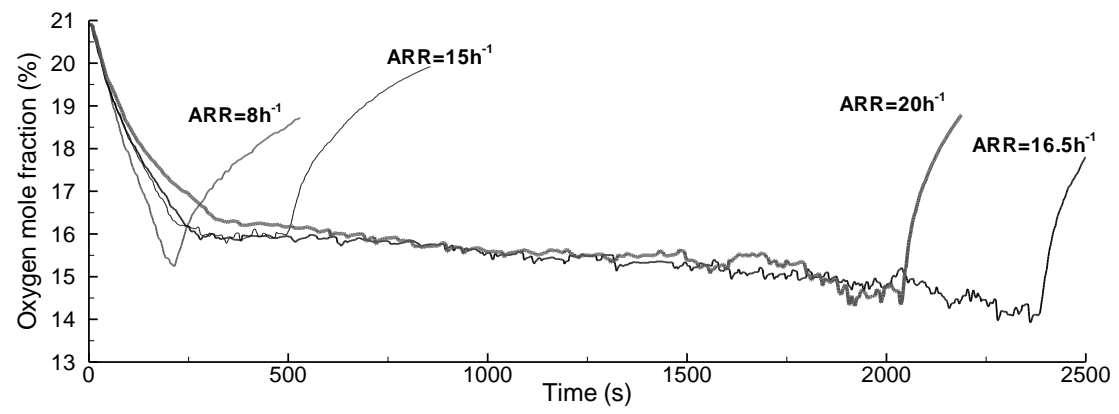

Fig. 6. Oxygen mole fraction in the lower part of the FE corner vs. time for different air renewal rates.

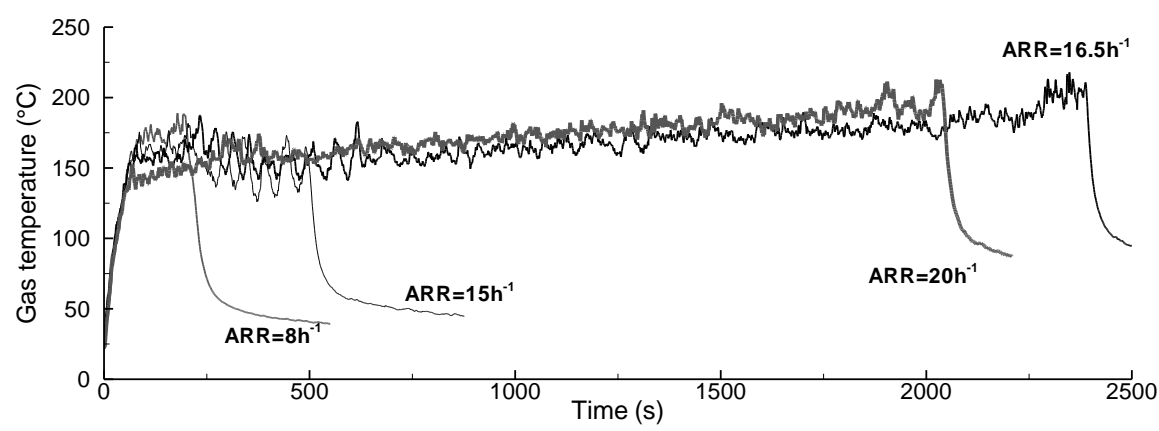

Fig. 7. Time evolution of gas temperature in the FE corner at a height of $0.95 \mathrm{~m}$ for different air renewal rates.
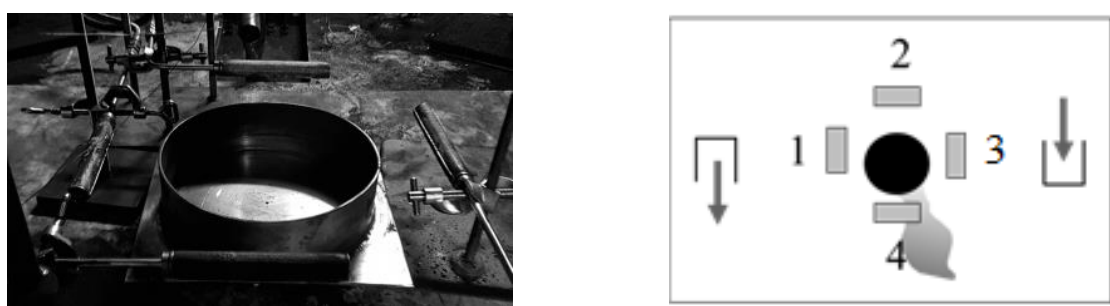

Fig. 8. Picture and schematic diagram of the positions of oxygen analyzers near the fuel pan.

Table 1 Frequencies (in $\mathrm{mHz}$ ) of $\mathrm{LF}$ oscillations vs. ARR for the MLR, the differential pressure, the oxygen mole fraction in the exhaust duct, and the gas temperature in the $\mathrm{FE}$ corner at a height of $0.95 \mathrm{~m}$.

\begin{tabular}{|l|l|l|l|l|l|}
\hline \multirow{2}{*}{ Variable } & \multicolumn{4}{|l|}{ ARR $\left(\mathrm{h}^{-1}\right)$} \\
\cline { 2 - 6 } & 10 & 12.5 & 15 & 16.5 & 18 \\
\hline $\mathrm{MLR}$ & 17.2 & 18.2 & 20.8 & 21.7 & 24.4 \\
\hline$\Delta \mathrm{p}$ & 16.7 & 19.2 & 20.0 & 21.3 & 24.4 \\
\hline $\mathrm{X}_{\mathrm{O} 2}$ & 16.4 & 18.2 & 20.0 & 22.7 & 25.0 \\
\hline $\mathrm{T}$ & 16.7 & 18.5 & 20.4 & 23.3 & 25.6 \\
\hline
\end{tabular}

\section{FLAME \\ DISPLACEMENTS DEPENDENCE ON OXYGEN CONCENTRATION}

To correlate the movement of the flame outside the fuel pan to the oxygen level in the vicinity of the fuel pan, experiments were carried out, positioning four oxygen analyzers at $5 \mathrm{~cm}$ from the side edges of the pan and a height of $5 \mathrm{~cm}$, which corresponds to the top of the pan (Fig. 8). Figure 9 shows the time evolution of oxygen mole fractions near the fuel pan.
In the first 200 seconds, the decrease of oxygen differs depending on the position of the gas analyzer. It appears clearly that the oxygen mole fraction measured by the oxygen analyzer 4 decreases more slowly than the others, which explains why the flame moved to the FE corner when it left the fuel pan, seeking oxygen. Although gas sampling near the reaction zone brought valuable information on the availability of oxygen for combustion, we observed that sucking the gas samples for analysis (here, with a flow rate of $0.126 \mathrm{~m}^{3} / \mathrm{h}$ for each analyzer), led to slight differences in the persistence and properties of LF oscillations (as shown by comparing the MLRs in Figs. 3 and 9). This explains why this invasive measurement of oxygen concentration near the reaction zone was abandoned thereafter.

\section{VENTILATION CONFIGURATION EFFECTS}

The effects of ventilation configuration on the oscillatory fire behavior are investigated in this section. A series of five tests is carried out varying the height of the air inlet location and the blowing 


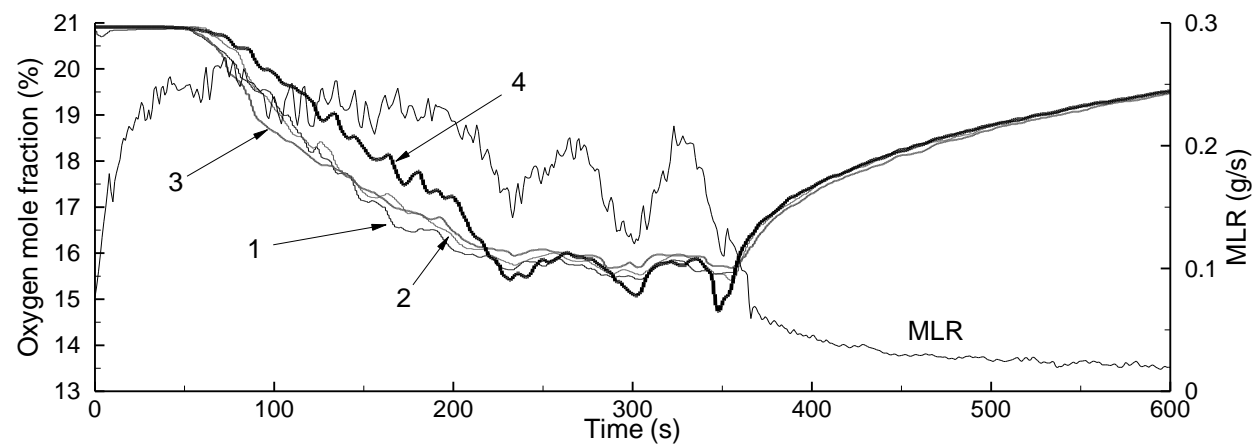

Fig. 9. Time evolution of oxygen mole fraction at different positions near the fuel pan (see Fig. 8 for the position of oxygen analyzers). For easier analysis, the MLR-time curve is superimposed on this figure.

direction (Table 2). For example, the test case 5 corresponds to the low air inlet location where the air flow was directed towards the Front wall (see Fig. 10). For all these tests, except for the ventilation configuration, all other things are equal: an ARR of $15 \mathrm{~h}^{-1}$, a heptane pool of $18 \mathrm{~cm}$ in diameter, with a lip height of $7 \mathrm{~mm}$. Here, we focus on a period where LF oscillations are observed, from 400 to $700 \mathrm{~s}$.

Table 2 Test Matrix.

\begin{tabular}{|c|l|l|l|l|l|}
\hline Test case & 1 & 2 & 3 & 4 & 5 \\
\hline Blowing direction & F & B & W & F & F \\
\hline $\begin{array}{c}\text { Average height of the center } \\
\text { of the air inlet duct (cm) }\end{array}$ & 74 & 74 & 74 & 54 & 14 \\
\hline
\end{tabular}

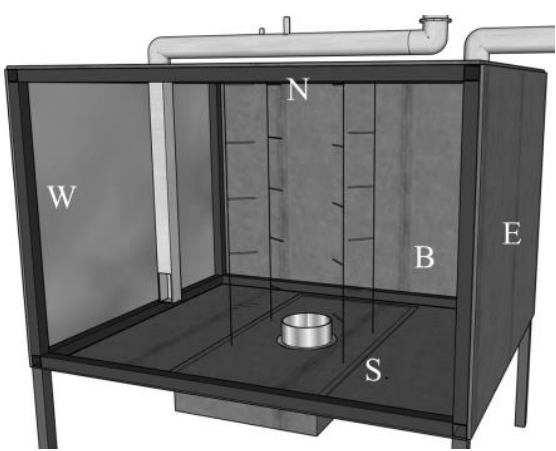

Fig. 10. Schematic diagram of the experimental setup in the ventilation configuration of test case 6 (view from the Front wall).

First let us examine the differences in MLR and LF oscillations caused by changing the blowing direction, which leads to comparing test cases 1 to 3 . Depending on the direction of the air flow entering the enclosure, the area where the flame positioned preferentially differs. The flame moves towards the corner FE for test case 1, whereas it moves towards the $\mathrm{BE}$ corner for test case 2 and towards the West wall for test case 3 (Fig. 11). In these experiments with a high inlet location, fresh air was not transported directly to the reaction zone, which explains why the flame does not move systematically towards the West wall. This suggests that the presence of oxygen near the fuel pan results from ventilation-induced flow recirculation and smoke mixing in the enclosure. Unfortunately, our measurements do not allow such an assessment.
In Fig. 12(a), the MLR is plotted versus time for test cases 1 to 3 . Changing the blowing direction does not influence the time-averaged MLR, nor the oscillation frequency. However, this leads to changes in the amplitude of LF oscillations, with average values of $0.053,0.070$ and $0.028 \mathrm{mHz}$ for test cases 1 to 3 , respectively. The lowest amplitude oscillations are observed for test case 3, which suggests a much more stable combustion. The height at which the inlet duct delivers fresh air is known to be an important factor that affects the MLR, and thus the heat release rate, and smoke layering (Backovsky et al., 1989). Comparative analysis of test cases 1, 4 and 5 confirm these observations. When the air-inlet location is lower, the quantity of air available for combustion is greater. Therefore, the combustion is more complete, and the cooling of the upper layer is lower (higher heat feedback), which leads to a higher MLR, as shown in Fig. 12(b). Air-inlet location also influences the LF oscillation properties. The lower the inlet location, the higher the frequency and the smaller the amplitude, suggesting a better equilibrium between the rates of air supply and fuel vapor supply. This finding can be compared with that of Kim et al. (1993) who found that the oscillation period becomes shorter as the ventilation factor increases.

\section{CONCLUSION}

Small-scale experiments have been conducted in forced ventilation enclosures, varying the air renewal rate and ventilation configuration and using a constant surface area of liquid fuel (here, heptane), to investigate the low-frequency oscillating burning regime. From the results, we made the following observations. The occurrence and persistence of LF oscillations are strongly dependent on the equilibrium between the air supply and the fuel vapor supply due to the heat feedback from the flame and enclosure to the fuel tray. These oscillations, in the order of about $20 \mathrm{mHz}$, are accompanied by large pressure variations and flame displacements out of the pan, toward regions where oxygen is present. An explanation of the LF oscillatory behavior was provided. As the ARR increases, three different fire regimes can be observed: (1) rapid extinction due to smoke filling; (2) LF oscillating combustion, where blow-off 


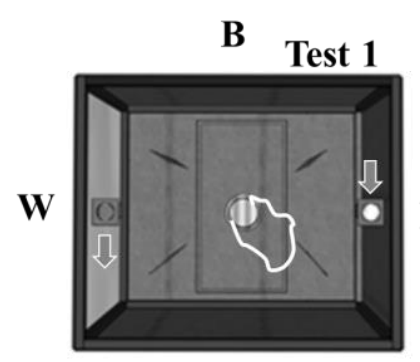

F

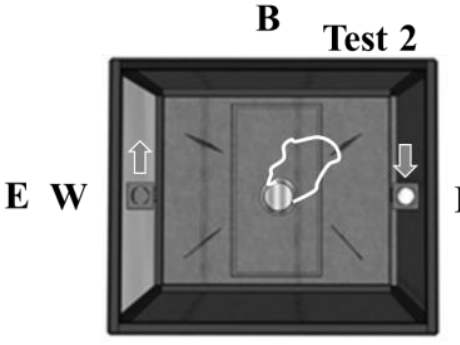

F

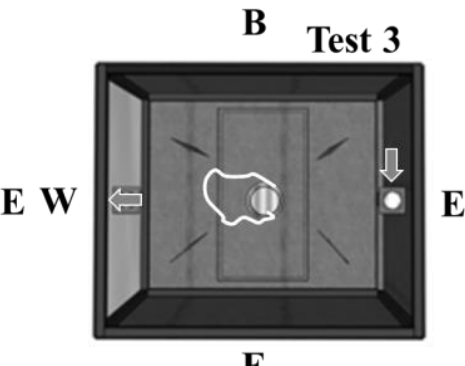

F

Fig. 11. Schematic diagrams showing the areas where the flame preferentially positioned for test cases 1 to 3 (top views).
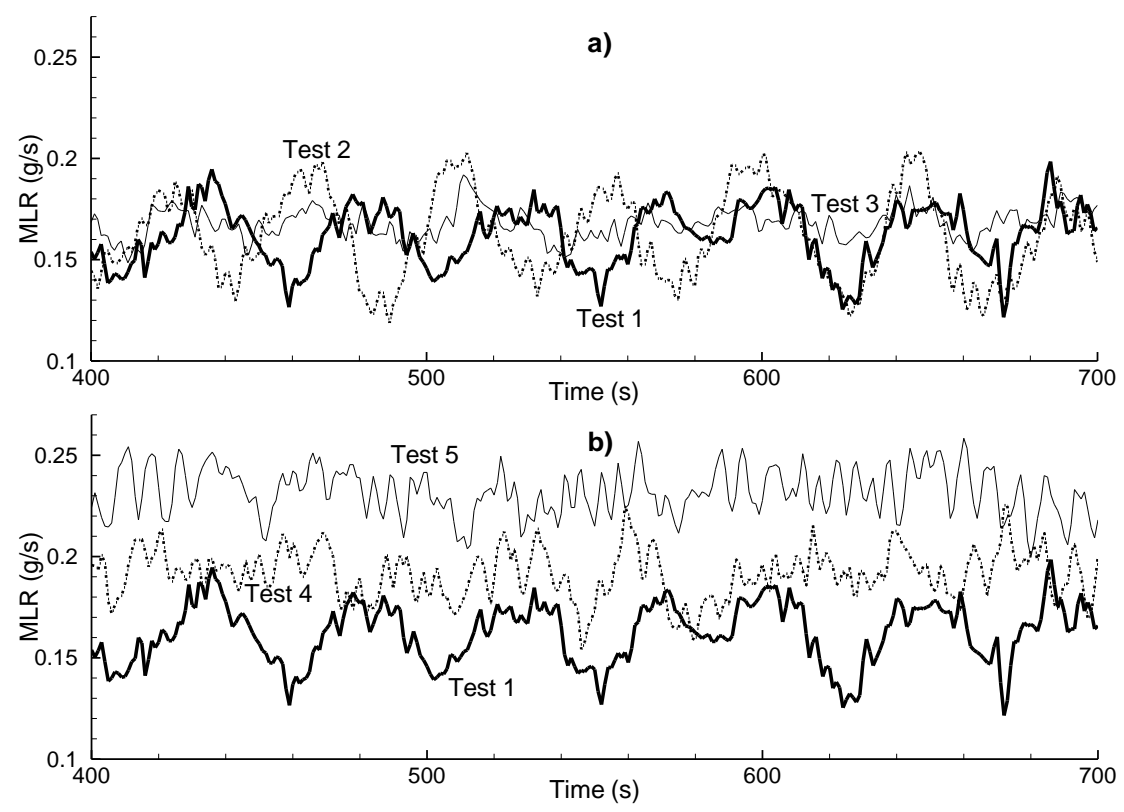

Fig. 12. MLR vs. time (a) for test cases 1 to 3, and (b) for test cases 1, 4 and 5.

extinction occurs after a few oscillations; and (3) LF oscillating combustion. In the oscillatory combustion regimes, the extinction is due to an enhancement of the burning rate resulting either from an increase of the heat feedback from the flame and enclosure to the fuel surface (regime 2) or from a thermal runaway caused by an increase of the heat transfer through the rim of the container (regime 3 ). It appears clearly that the frequency of the oscillations increases with ARR, while their amplitude decreases with rising ARR. In regime (3), the MLR increases with the ARR, due to an increase of the gas temperature, and thus of the heat feedback. However, although the air supply is significantly greater than the stoichiometrically required air, the burning rate is far from that calculated for free burning conditions, which indicates that only a part of the incoming air is available for combustion.

Changing the direction of the air flow entering the compartment leads to changes in the area where the flame migrates during the LF oscillatory regime. This reveals the complexity of the flow under forced ventilation, with recirculation and interaction with the reaction zone and the smoke layer.

Fire behavior is found to be sensitive to the air-inlet location. Lowering the inlet location promotes the availability of air for combustion and reduces the cooling of the hot gas layer. This leads to a more complete combustion and higher MLR. The balance between air supply and fuel vapor supply is better, leading to oscillations with higher frequency and lower amplitude. Further experimental and numerical work is in progress to investigate the link between flow dynamics and fire behavior in mechanically-ventilated compartments.

\section{ACKNOWLEDGEMENTS}

The authors would like to thank the Provence-AlpesCote d'Azur Region for its financial support.

\section{REFERENCES}

Audouin, L., L. Rigollet, H. Prétrel, W. Le Saux, and M. Röwekamp (2013). OECD PRISME project, fires in confined and ventilated nuclear-type multi-compartments. Fire Safety Journal 62, 80101.

Babrauskas, V. (1983). Estimating large pool fire burning rates. Fire Technology 19, 251-261. 
Backovsky, J., K. L. Foote and N. J. Alvares (1989). Temperature profiles in forced-ventilation enclosure fires. Fire Safety Science Proceedings of the Second International Symposium 315-324.

Bertin, G., J. M. Most and M. Coutin (2002). Wall fire behavior in an under-ventilated room. Fire Safety Journal 37, 615-630.

He, Q., C. Li, S. Lu, C. Wang and J. Zhang (2015). Pool fires in a corner ceiling vented cabin: ghosting flame and corresponding fire parameters. Fire Technology 51, 537-552.

Kim, K., H. Ohtani and Y. Uehara (1993). Experimental study on oscillating behavior in a small-scale compartment fire. Fire Safety Journal 20, 377-384.

Loo, A., A. Coppalle and P. Aîné (2013). Flame extinction in a ventilation-controlled compartment. Procedia Engineering 62, 301308.

Matsuyama, K., S. Okinaga, Y. Hattori and H. Suto (2015). Experimental study on fire behavior in a compartment under mechanical ventilated conditions: the effects of air inlet position. Proceedings of the Tenth Asia-Oceania Symposium on Fire Science and Technology, 111-119.

McCaffrey, B. J. and G. Heskestad (1976). A robust bidirectional low-velocity probe for flame and fire application. Combustion and Flame 26, 125127.

Mizukami, T., Y. Utiskul and J. G. Quintiere (2016). A compartment burning rate algorithm for a zone model. Fire Safety Journal 79, 57-68.

Prétrel, H., S. Suard and L. Audouin (2016). Experimental and numerical study of low frequency oscillatory behavior of large-scale hydrocarbon pool fire in a mechanically ventilated compartment. Fire Safety Journal 83,
38-53.

Sugawa, O., K. Kawagoe, Y. Oka and I. Ogahara (1989). Burning behavior in a poorly ventilated compartment fire- ghosting fire. Fire Science and Technology 9, 5-14.

Takeda, H. (1985). Oscillatory phenomenon and inverse temperature profile appearing in compartment fires. Combustion and Flame 61, 103-105.

Takeda, H. and K. Akita (1981). Critical phenomenon in compartment fires with liquid fuels. Symposium (International) on Combustion 18, 519-527.

Utiskul, Y. and J. G. Quintiere (2008). An application of mass loss rate with fuel response effects in fully-developed compartment fires. Fire Safety Science - Proceedings of the Ninth International Symposium, 827-838.

Utiskul, Y., J. G. Quintiere, A. S. Rangwala, B. A. Ringwelski, K. Wakatsuki and T. Naruse (2005). Compartment fire phenomena under limited ventilation. Fire Safety Journal 40, 367390.

Wakatsuki, K. (2001). Low ventilation small-scale compartment fire phenomena: ceiling vents. MS thesis, Department of Fire Protection Engineering, University of Maryland, College Park.

Zabetakis, M. G. and D. S. Burgess (1961). Research on Hazards Associated with the Production of and Handling of Liquid Hydrogen, U.S. Bureau of Mines Report, RI 5705.

Zukoski, E. E., B. M. Cetegen and T. Kubota (1984). Visible structure of buoyant diffusion flames. Symposium (International) on Combustion 20,361-36. 